\title{
Pulmonary benign metastasizing leiomyoma: a case report and literature review
}

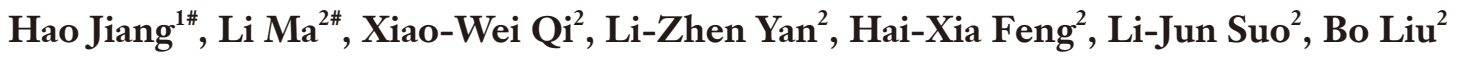 \\ ${ }^{1}$ Department of Emergency Medicine, The Second Hospital of Nanjing, Nanjing University of Chinese Medicine, Nanjing, China; ${ }^{2}$ Department \\ of Pulmonary and Critical Care Medicine, Zibo City Key Laboratory of Respiratory Infection and Clinical Microbiology, Zibo City Engineering \\ Technology Research Center of Etiology Molecular, Zibo, China \\ \#These authors contribute equally to this work. \\ Correspondence to: Li-Jun Suo; Bo Liu. Department of Pulmonary and Critical Care Medicine, Zibo City Key Laboratory of Respiratory Infection and \\ Clinical Microbiology, Zibo City Engineering Technology Research Center of Etiology Molecular, Linzi District People’s Hospital, Zibo 255400, \\ China. Email: suolij@hotmail.com; lwmx@foxmail.com.
}

\begin{abstract}
Benign metastasizing leiomyoma (BML) is a rare condition that occurs mainly in premenopausal women and is characterized most commonly by pulmonary metastases. Here, we report the case of a 45 -yearold woman who presented with multiple bilateral pulmonary nodules on chest examination during a health checkup 13 years after myomectomy. This patient has a normal menstrual cycle, moderate anemia, and no obvious respiratory symptoms. Serum concentrations of cancer markers such as carcinoembryonic antigen, neuron specific enolase, cytokeratin 19 fragments, and pro-gastrin-releasing peptide were within normal limits. Color doppler ultrasound was also performed, several hypoechoic regions were found in uterine bodies and cavity. The computed tomography (CT)-guided lung biopsy was used for histopathological examination. Immunohistochemical staining revealed BML which were positive for smooth muscle antibody, desmin, vimentin, estrogen and progesterone receptors, and $\mathrm{Ki}-67$ positive rate of about $1 \%$. Hysterectomy and bilateral adnexectomy were performed as a part of treatment. The lung nodules were meticulously monitored at follow-up. Three months later, the repeat CT scan showed that the nodules had reduced in size, and no new nodules had appeared, 1 year later, CT scan showed no obvious changes in lung nodules. This study is of great significance as the results will be helpful in diagnosing and treating future pulmonary benign metastasizing leiomyoma (PBML) cases.
\end{abstract}

Keywords: Benign metastasizing leiomyoma (BML); myomectomy; pulmonary metastases; lung biopsy; case report

Submitted Apr 02, 2020. Accepted for publication Jul 31, 2020.

doi: 10.21037/apm-20-878

View this article at: http://dx.doi.org/10.21037/apm-20-878

\section{Introduction}

Benign metastasizing leiomyomas (BML) are rare tumors which mainly occur in premenopausal women. Additionally, it has been reported in post-menopausal women, although extremely rarely $(1,2)$. BML is often associated with distant metastases from the uterus, and lung metastases are the most common site of metastases $(3,4)$, and this is usually called pulmonary benign metastasizing leiomyoma (PBML). The onset of the disease is undetectable (5). Most patients have no symptoms (6), and rarely, patients are symptomatic with cough, dyspnea, chest pain, pneumothoraces, or hemoptysis (7-9). PBML is quite difficult to diagnose by simple medical imaging or physical examination, and previously, it was often misdiagnosed as pneumonia, bronchitis, pulmonary tuberculosis, or metastasizing lung cancer. Therefore, lung biopsy is the only way to confirm this disease, and histopathologic and immunohistochemical staining is the standard diagnostic procedure for PBML. In this case report, we present the complete laboratory examination and imaging and pathological data of pulmonary and uterine 

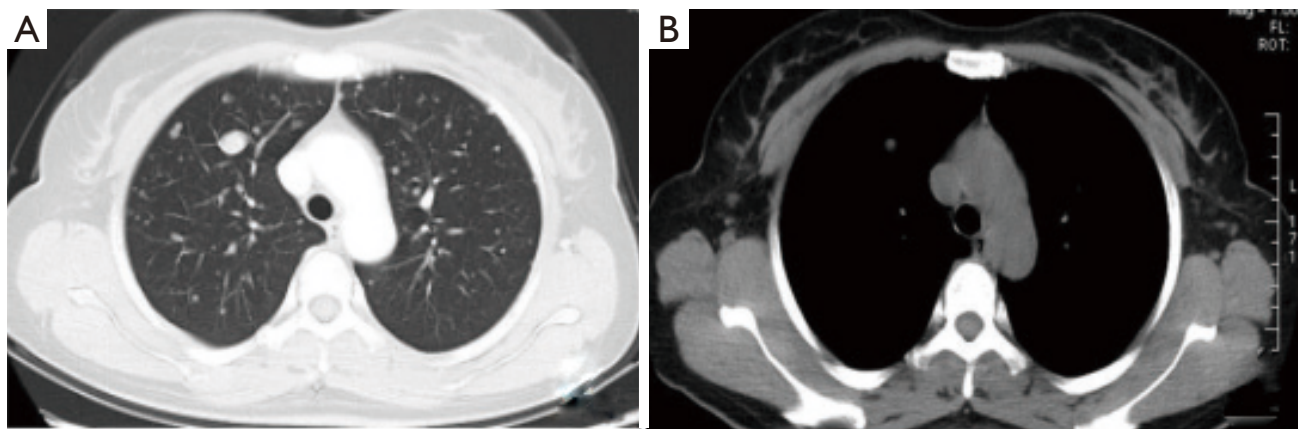

Figure 1 Chest CT scan. (A) Diffuse miliary shadow in both lungs; (B) the mediastinal window scan also shows multiple nodules. CT, computed tomography.
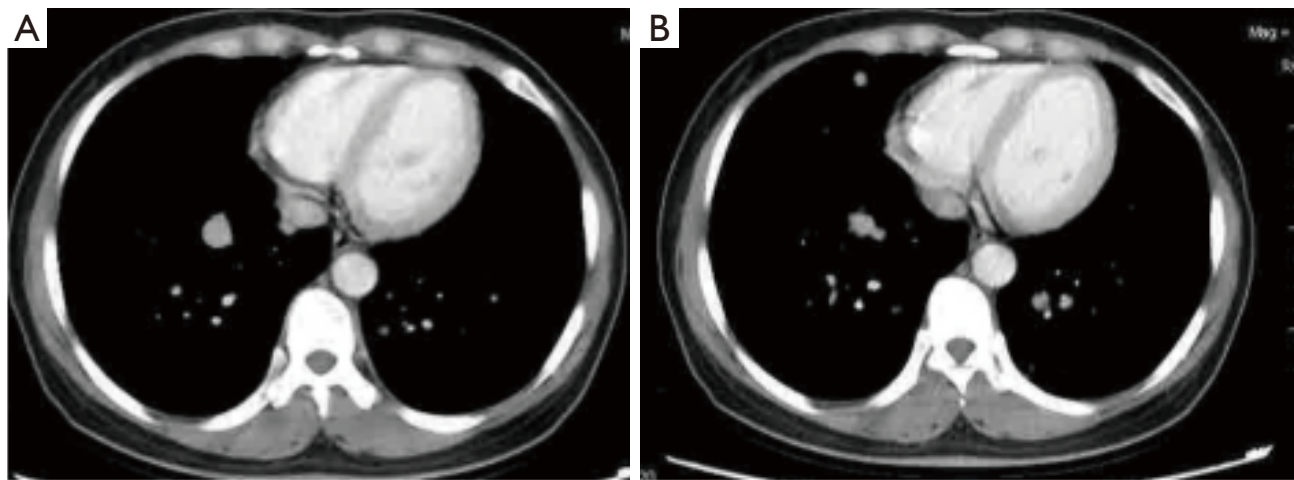

Figure 2 No enhancement in arterial phase under enhanced chest CT. CT, computed tomography.

tumors including the clinical pathology, imaging features, bronchoscopy results, immunohistochemical staining features, diagnosis, and treatment. In addition, we have reviewed the literature associated with PBML.

We present the following case in accordance with the CARE reporting checklist (available at http://dx.doi. org/10.21037/apm-20-878).

\section{Case presentation}

A 45-year-old woman presented with multiple pulmonary nodules by chest computed tomography (CT). She had no cough, sputum, dyspnea, hemoptysis, chest pain, fever, or other symptoms. Thirteen years ago, she underwent hysteromyomectomy immediately after cesarean. The patient had regular menstruation since 13 years of age that occurred every 27-28 days for 6-7 days. Routine blood test showed that hemoglobin was $88 \mathrm{~g} / \mathrm{L}$, and the number of red blood cells was $4.26 \times 10^{12} / \mathrm{L}$. Other laboratory examinations were almost normal. The blood sedimentation rate, C-reactive protein, procalcitonin, blood biochemistry, and blood coagulation function were within the normal range. Serum concentrations of cancer markers such as carcinoembryonic antigen, neuron specific enolase, cytokeratin 19 fragments, and pro-gastrin-releasing peptide were within normal limits. The sputum and alveolar lavage fluid were free of bacteria, fungi, and tuberculosis. The chest CT (Figure 1) revealed multiple nodules of different size. In enhancement CT after injection of contrast agent (Figure 2), there was no enhanced lesion in the arterial phase and no mediastinal and hilar lymphadenopathy. The results of bronchoscopy were normal (Figure 3).

The pulmonary diseases are difficult to diagnose. Percutaneous lung biopsy under CT was used for pathological examination. Hematoxylin eosin (HE) staining (Figure 4) showed spindle-shaped smooth muscle tumor cells. Immunohistochemical staining (Figure 5) showed smooth muscle antibody (SMA) $(+)$, desmin $(+)$, vimentin $(+)$, estrogen receptor (ER) $(+)$, progesterone receptor (PR) (+), HMB-45 (-), CD34 (-), S-100 (-), and Ki-67 

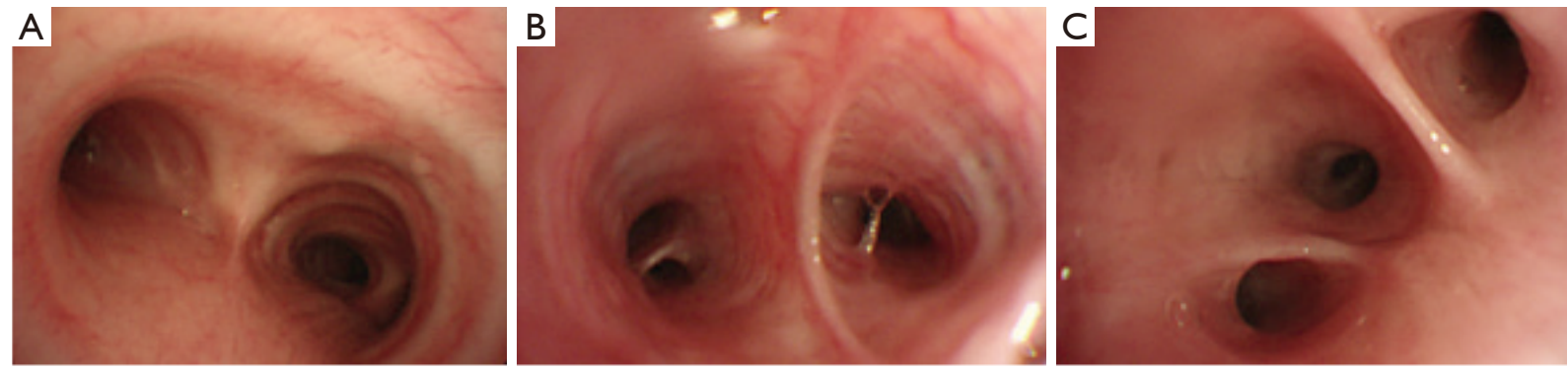

Figure 3 Fiberoptic bronchoscopy showed smooth bronchial mucosa, no abnormality seen.
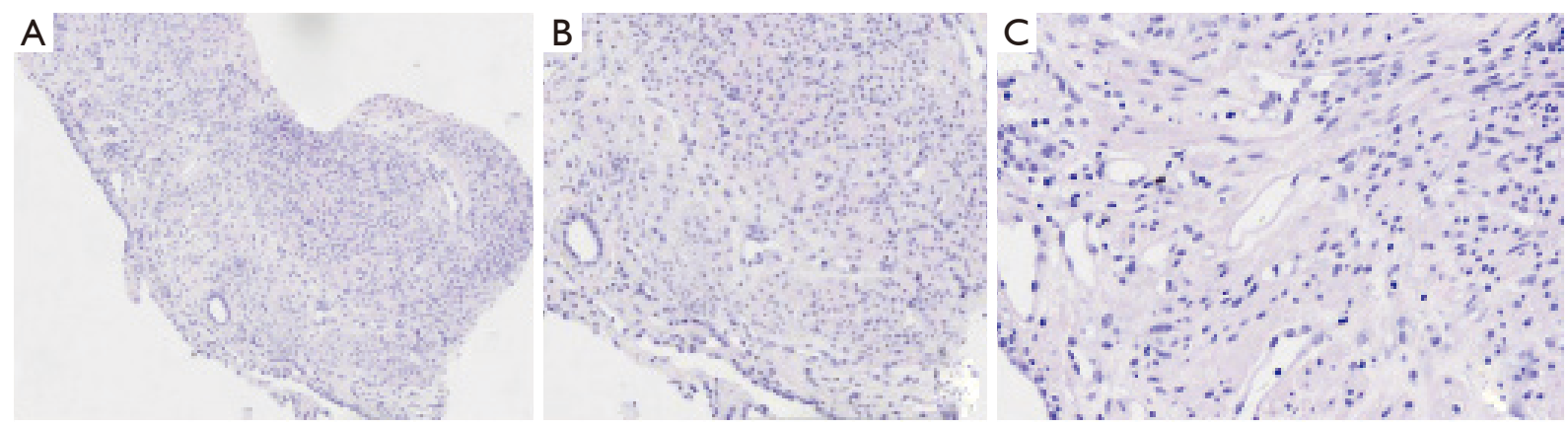

Figure 4 Pathological findings in the right lung through percutaneous lung biopsy by HE staining showed spindle smooth muscle cells of different differentiations. The cell morphology was consistent, without atypia and mitoses (A, $\times 10 ; \mathrm{B}, \times 20 ; \mathrm{C}, \times 40)$.

positive rate of about $1 \%$. Combining patient's medical history with the examination results, she was diagnosed with PBML. Color doppler ultrasound was performed. Several hypoechoic regions were found in uterine bodies and cavity. All procedures performed in studies involving human participants were in accordance with the ethical standards of the institutional and/or national research committee(s) and with the Helsinki Declaration (as revised in 2013). Written informed consent was obtained from the patient for publication of this study and any accompanying images.

\section{Treatment and follow-up}

Bilateral adnexectomy with hysterectomy was performed. Postoperative pathology showed 12 leiomyomas of different sizes $(0.4-2.8 \mathrm{~cm}$ in diameter) in the subserous, intermuscular, and submucous regions (Figure 6). After 3 months of follow-up, the patient had no respiratory symptoms. Chest CT (Figure 7) showed a reduction in lung nodules. The timeline (Figure 8) shows the patient's diagnosis and treatment process.

\section{Discussion}

Hysteromyoma is a common gynecologic benign tumor which mostly occurs in women over 30 years of age. Distant metastases are very rare. Most of the patients have a history of uterine leiomyoma surgery. Lung is the most common metastatic organ. Extra-pulmonary organ metastasis to organs such as skin, soft tissue, omentum, inferior vena cava, right atrium, lymph node, and skeletal muscle may occur at the same time or after lung metastasis (10-13). The lung lesions are usually identified several years (from 1 month to more than 20 years) after hysterectomy or myomectomy, and the growth rate of these tumors is slow (14). The patient in this study was found to have pulmonary nodules 13 years after myomectomy. PBML is a rare benign metastatic disease, and its pathogenesis is still controversial and conjectural. Related studies suggest that it is transmitted from uterine tissues through lymph or blood, and this has been supported by molecular studies (15). Wu et al. (16) used parallel sequencing and genome-wide copy number to detect lung and uterine leiomyoma in synchronized tissue samples. It was found that the somatic mutation and copy number aberrations were the same in 

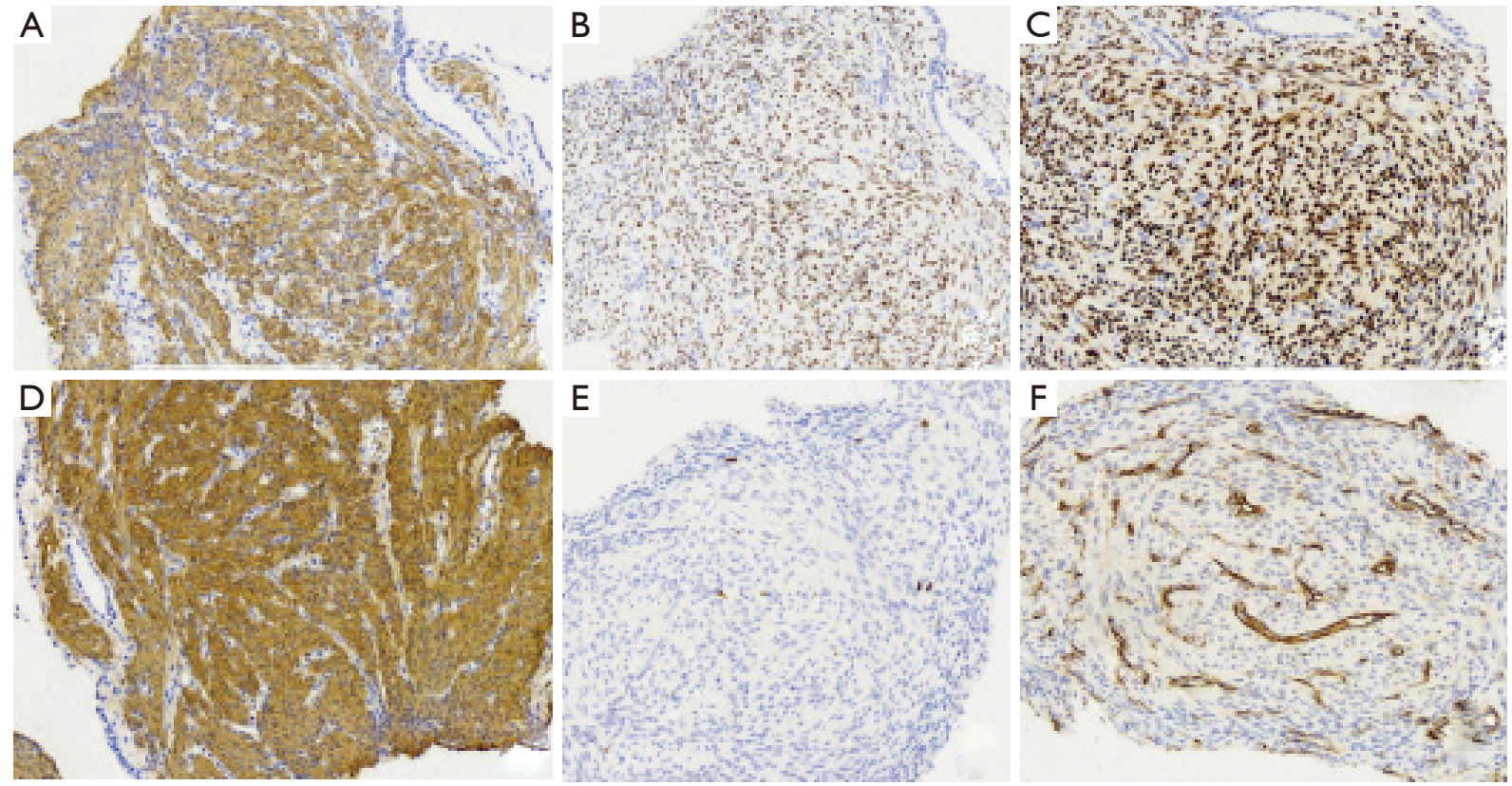

Figure 5 Groups of immunohistochemical staining results $(\times 100)$. (A) Strong positivity for desmin throughout the tumor suggested that the tumor was derived from smooth muscle; (B) strong positivity for the estrogen receptor (ER) throughout the tumor suggested that the tumor cells originated in the uterus and were regulated by the ER; (C) strong positivity for the progesterone receptor (PR) throughout the tumor suggested that the tumor cells originated in the uterus and were regulated by the PR; (D) strong positivity for SMA showed that the tumor was derived from smooth muscle; (E) weak positivity for Ki-67 (1\%) suggested that the low proliferation index of tumor cells; (F) negative for $\mathrm{CD} 34^{+}$suggested that the tumor cells was not malignant angiogenic.
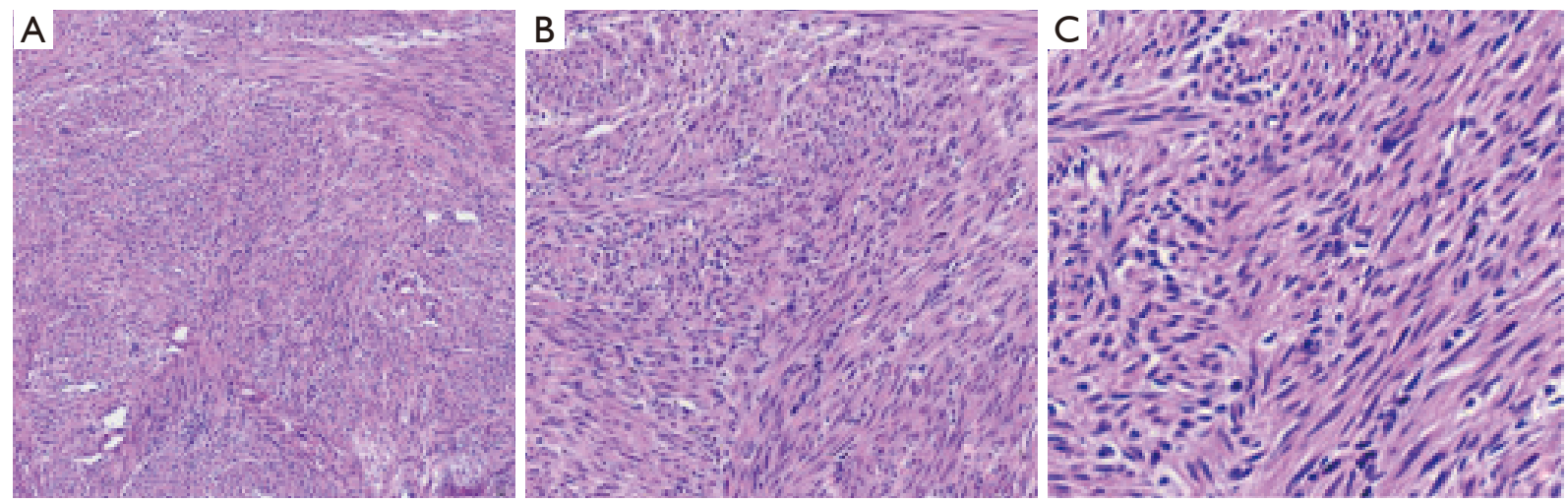

Figure 6 Uterine tumor by HE staining showed spindle smooth muscle cells $(A, \times 10 ; B, \times 20 ; C, \times 40)$.

paired pulmonary and uterine leiomyomata. Moreover, similar chromosomal aberrations were found in 2 sites (17) which confirmed the genetic relationship between these lesions. Several studies have shown that PBML has the same clonal origin as primitive uterine leiomyoma (16-19). A potentially deleterious somatic heterozygous mutation in the bone morphogenetic protein $8 \mathrm{~B}$ gene may play a facilitatory role in the metastasis of BML (20).

The growth of PBML mainly depends on the hormones estrogen and progesterone since estrogen and PRs are positive in most cases (21). The tumor progression is stimulated by estrogen and suppressed by progesterone. It 

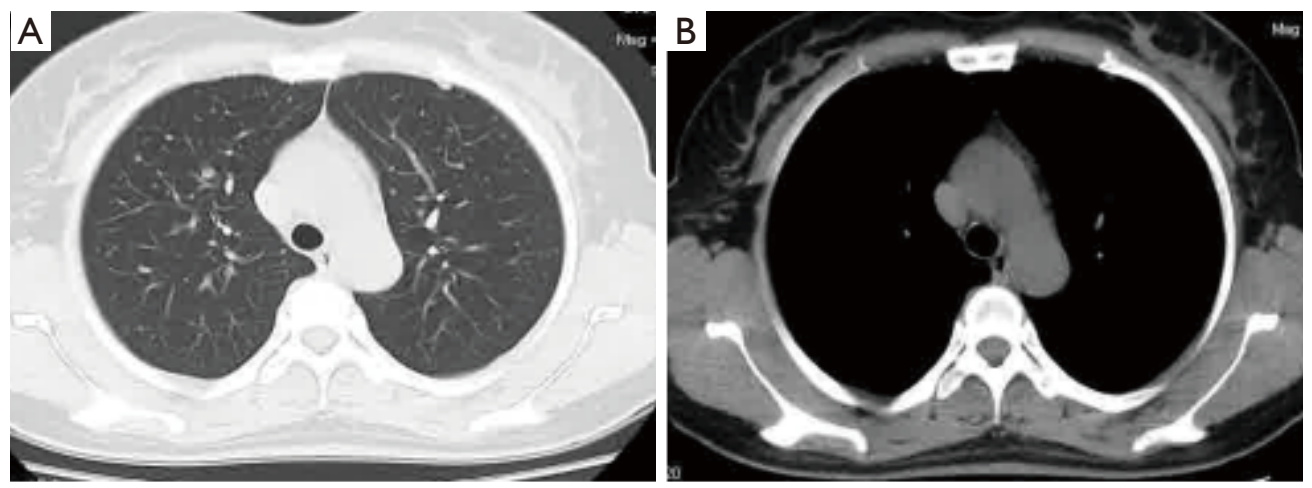

Figure 7 Chest CT examination indicates that pulmonary nodules are smaller than the anterior after three months. CT, computed tomography.

Past medical history: 13 years ago, she uderwent hysteromyomectomy immediately after cesarean

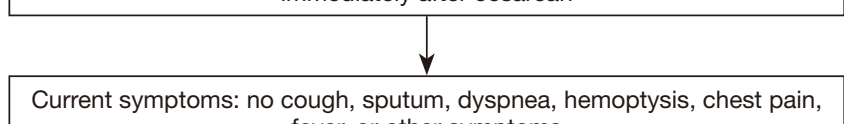

fever, or other symptoms

Dagnostic test results : The chest CT revealed multiple nodules of different size with no enhanced lesion and no mediastinal and hilar lymphadenopathy. The results of bronchoscopy were normal. Pathological results of lung biopsy showed spindle-shaped smooth muscle tumor cells, immunohistochemical staining showed smooth muscle antibody (SMA) (+), Desmin (+), Vimentin (+), estrogen receptor (ER) (+), progesterone receptor (PR) (+), HMB-45 (-), CD34 (-), S-100 (-), and $\mathrm{Ki}-67$ positive rate of about $1 \%$

Interventions: Bilateral adnexectomy with hysterectomy was performed, postoperative pathology showed 12 leiomyomas of different sizes $(0.4-2.8 \mathrm{~cm}$ in diameter ) in the subserous, intermuscular, and submucous

Follow-up events: 3 months later, the patient had no respiratory symptoms. Chest CT showed a reduction in lung nodules

Figure 8 The timeline of patient diagnosis and treatment.

regresses spontaneously after pregnancy or menopause (22). The onset of PBML is undetectable, and most are found during physical examination. Most patients are asymptomatic or have mild symptoms of cough, expectoration, and chest tightness $(7,23)$. Chest pain, pneumothorax, and hemoptysis may occur when the tumor increases in size $(24,25)$. A PBML patient, who suffered from respiratory failure, presented with bilaterally or voluminous pulmonary and pleural lesions with miliary nodular pattern in the lungs $(26,27)$.

Typical radiological findings of BMLs show numerous well-circumscribed solid pulmonary nodules of different sizes that are scattered within the bilateral, unilaterally bilateral, or unilaterally normal lung tissues but with no calcification or contrast enhancement $(1,28)$. A few cases may present as broad miliary nodules in both lungs, similar to the imaging features of miliary tuberculosis (26). Scarce imaging features including single or multiple cystic and vacuolar cavities are found in the lungs $(29,30)$. Nodules with diffused distribution in the bilateral lung with thinwalled cystic lesions and imaging features similar to lymphangioleiomyomatosis are rarely found (31). The present case was characterized by multiple solid nodules of different sizes in both lungs with no enhancement on enhanced chest CT scan. The imaging features of PBML should be distinguished from malignant metastasis of lung, primary lung cancer, lung tuberculosis, sarcoidosis, and lymphangioleiomyomatosis. 18-FDG-positron emission tomography (PET)/CT imaging is significant in the differential diagnosis of PBML and malignant diseases (4). We reviewed the literature for PET/CT findings in published cases of PBML. In 33 cases, there was no or little FDG uptake, while in three cases, there was uptake. On study reported that several patients demonstrated quiescent clinical course with a lack of 18-FDG uptake, and one patient exhibited aggressive cell proliferation with high uptake of 18-FDG (32). However, the sensitivity of PET-CT to small pulmonary nodules was poor, and a slight increase in metabolic values could not completely exclude malignant tumors. The case of primary lung adenocarcinoma with PBML indicates that one needs to be vigilant in the case of multiple pulmonary nodules $(33,34)$. The misdiagnosis can be avoided by early pathological examination. 
Pathology combined with immunohistochemistry is the key for diagnosing PBML. According to the size and location of pulmonary nodules, CT-guided lung biopsy or surgical resection should be selected. PBML has the same histological characteristics as uterine leiomyoma under microscope and presents as spindle smooth muscle cells, arranged in crossover or diffuse bundles, with no significant nuclear abnormalities, mitosis, or necrosis in the tumor cells (35). However, these morphological features are not specific because many mesenchymal tumors and epithelial tumors can have similar aspects. Therefore, immunohistochemistry is the key to accurate diagnosis. The typical immunophenotypes of PBML cells include SMA $(+)$, desmin (+), ER (+), and PR (+), whereas Ki-67 index is generally less than $1 \%$. Other smooth muscle tumors such as uterine leiomyosarcoma have similar immunophenotypes, but may have high cellular heterogeneity, necrosis, and mitotic index, in addition to lack of ER and PR expression. The morphology of solitary pulmonary fibrous tumor is similar to PBML, but its $\mathrm{CD} 34^{+}$expression is positive, and ER and smooth muscle markers are negative. In recent years, pathological, immunohistochemical, and genetic studies have revealed the pathogenesis and characteristics of the disease. In this study, the pathological specimens of the lung and uterus confirmed the homology of the disease.

There is no standard treatment or definite treatment guidelines for patients with BML because of the extremely low incidence of the disease. Previously, surgery and hormone therapy were used. For single or multiple pulmonary lesions, surgical resection is effective, and rare recurrent nodules were reported (36). Generalized hormone therapy is designed to regulate estrogen and progesterone levels in patients including adnexectomy and oral medication. Adnexectomy can control tumor growth and can be used for treating premenopausal women (37). Drug therapy has been shown to reduce the size of the tumor and improve the pulmonary function of patients who cannot be undergo surgery $(7,23,38)$. However, most follow-up results demonstrated that the lung nodules were stable or reduced in size, and complete remission was not reported. In clinical work, we should choose individualized treatment and patient monitoring.

\section{Conclusions}

In summary, the management of PBML is in the exploratory stage because of low incidence of this disease.
The possibility of PBML should be considered in women who have a history of hysteromyoma and subsequently, nodular lesions are found in the lung. The medical history and clinical examination data should be used to establish the pathology and origin of the disease as early as possible. In addition, individualized treatment and long-term surveillance is important to prevent disease progression. This study is of great significance as the results will be helpful in diagnosing and treating future PBML cases.

\section{The strengths and limitations of this case report}

Detailed previous medical history, comprehensive examination and multi-disciplinary collaboration are the key elements of the diagnosis, the shortcoming is that the estrogen and progesterone values of patients before and after surgery are not monitored.

\section{Acknowledgments}

Funding: This work was supported by Shandong Medical and Health Technology Development Project (2018WS006).

\section{Footnote}

Reporting Checklist: The authors have completed the CARE reporting checklist. Available at http://dx.doi.org/10.21037/ apm-20-878

Peer Review File: Available at http://dx.doi.org/10.21037/ apm-20-878

Conflicts of Interest: All authors have completed the ICMJE uniform disclosure form (available at http://dx.doi. org/10.21037/apm-20-878). The authors report nonfinancial support from Shandong Medical and Health Technology Development Project, during the conduct of the study.

Ethical Statement: The authors are accountable for all aspects of the work in ensuring that questions related to the accuracy or integrity of any part of the work are appropriately investigated and resolved. All procedures performed in studies involving human participants were in accordance with the ethical standards of the institutional and/or national research committee(s) and with the Helsinki 
Declaration (as revised in 2013). Written informed consent was obtained from the patient for publication of this study and any accompanying images.

Open Access Statement: This is an Open Access article distributed in accordance with the Creative Commons Attribution-NonCommercial-NoDerivs 4.0 International License (CC BY-NC-ND 4.0), which permits the noncommercial replication and distribution of the article with the strict proviso that no changes or edits are made and the original work is properly cited (including links to both the formal publication through the relevant DOI and the license). See: https://creativecommons.org/licenses/by-nc-nd/4.0/.

\section{References}

1. Efared B, Atsame-Ebang G, Sani R, et al. Unexpected pulmonary tumor: metastasis from a benign uterine leiomyoma in a post-menopausal woman: a case report. BMC Res Notes 2017;10:662.

2. Jo HC, Baek JC. Case of pulmonary benign metastasizing leiomyoma from synchronous uterine leiomyoma in a postmenopausal woman. Gynecol Oncol Rep 2018;26:33-6.

3. Chen S, Liu RM, Li T. Pulmonary benign metastasizing leiomyoma: a case report and literature review. J Thorac Dis 2014;6:E92-8.

4. Abu Saadeh F, Riain CO, Cormack CM, et al. Lung metastases from benign uterine leiomyoma: does 18-FDG-PET/CT have a role to play? Ir J Med Sci 2019;188:619-24.

5. Wei WT, Chen PC. Benign metastasizing leiomyoma of the lung: A case report and literature review. Oncol Lett 2015;10:307-12.

6. Goto T, Maeshima A, Akanabe K, et al. Benign metastasizing leiomyoma of the Lung. Ann Thorac Cardiovasc Surg 2012;18:121-4.

7. Rivera JA, Christopoulos S, Small D, et al. Hormonal manipulation of benign metastasizing leiomyomas: report of two cases and review of the literature. J Clin Endocrinol Metab 2004;89:3183-8.

8. Zhang J, Dong A, Cui Y, et al. Diffuse cavitary benign metastasising leiomyoma of the lung. Thorax 2019;74:208-9.

9. Hann M, Manacheril R, St Pierre J, et al. Recurrent pneumothoraces in a patient with pulmonary benign metastasizing leiomyoma. Ochsner J 2017;17:284-7.

10. Ma H, Cao J. Benign pulmonary metastasizing leiomyoma of the uterus: a case report. Oncol Lett 2015;9:1347-50.
11. Consamus EN, Reardon MJ, Ayala AG, et al. Metastasizing leiomyoma to heart. Methodist Debakey Cardiovasc J 2014;10:251-4.

12. Vaquero ME, Magrina JF, Leslie KO. Uterine smooth muscle tumors with unusual growth patterns. J Minim Invasive Gynecol 2009;16:263-8.

13. Meddeb M, Chow RD, Whipps R, et al. The Heart as a Site of Metastasis of Benign Metastasizing Leiomyoma: Case Report and Review of the Literature. Case Rep Cardiol 2018;2018:7231326.

14. Mahmoud MS, Desai K, Nezhat FR. Leiomyomas beyond the uterus; benign metastasizing leiomyomatosis with paraaortic metastasizing endometriosis and intravenous leiomyomatosis: a case series and review of the literature. Arch Gynecol Obstet 2015;291:223-30.

15. Awonuga AO, Shavell VI, Imudia AN, et al. Pathogenesis of benign metastasizing leiomyoma: a review. Obstet Gynecol Surv 2010;65:189-95.

16. Wu RC, Chao AS, Lee LY, et al. Massively parallel sequencing and genome-wide copy number analysis revealed a clonal relationship in benign metastasizing leiomyoma. Oncotarget 2017;8:47547-54.

17. Bowen JM, Cates JM, Kash S, et al. Genomic imbalances in benign metastasizing leiomyoma: characterization by conventional karyotypic, fluorescence in situ hybridization, and whole genome SNP array analysis. Cancer Genet 2012;205:249-54.

18. Lin J, Song X, Liu C. Pelvic intravascular leiomyomatosis associated with benign pulmonary metastasizing leiomyoma: clinicopathologic, clonality, and copy number variance analysis. Int J Gynecol Pathol 2014;33:140-5.

19. Patton KT, Cheng L, Papavero V, et al. Benign metastasizing leiomyoma: clonality, telomere length and clinicopathologic analysis. Mod Pathol 2006;19:130-40.

20. Sõritsa D, Teder H, Roosipuu R, et al. Whole exome sequencing of benign pulmonary metastasizing leiomyoma reveals mutation in the BMP8B gene. BMC Med Genet 2018;19:20.

21. Maruo T, Ohara N, Wang J, et al. Sex steroidal regulation of uterine leiomyoma growth and apoptosis. Hum Reprod Update 2004;10:207-20.

22. Arai T, Yasuda Y, Takaya T, et al. Natural decrease of benign metastasizing leiomyoma. Chest 2000;117:921-2.

23. Wang HP, Shi JH, Zhang L. Clinical analysis of 7 cases of benign metastatic leiomyomatosis of lung. Chin J Intern Med 2017;56:490-4.

24. Ponea AM, Marak CP, Goraya H, et al. Benign metastatic leiomyoma presenting as a hemothorax. Case Rep Oncol 
Med 2013;2013:504589.

25. Miyazaki M, Nakayama A, Noda D, et al. Difficulty in complete transarterial embolization for pulmonary benign metastasizing leiomyoma with massive hemoptysis. Jpn J Radiol 2014;32:53-7.

26. Ofori K, Fernandes H, Cummings M, et al. Benign metastasizing leiomyoma presenting with miliary pattern and fatal outcome: Case report with molecular analysis \& review of the literature. Respir Med Case Rep 2019;27:100831.

27. Pastré J, Juvin K, Grand B, et al. Pulmonary benign metastasizing leiomyoma presented as acute respiratory distress. Respirol Case Rep 2017;5:e00216.

28. Zong D, He W, Li J, et al. Concurrent benign metastasizing leiomyoma in the lung and lumbar spine with elevated standardized uptake value level in positron-emission tomography computed tomography: A case report and literature review. Medicine (Baltimore) 2018;97:e11334.

29. Loukeri AA, Pantazopoulos IN, Tringidou R, et al. Benign metastasizing leiomyoma presenting as cavitating lung nodules. Respir Care 2014;59:e94-7.

30. Choe YH, Jeon SY, Lee YC, et al. Benign metastasizing leiomyoma presenting as multiple cystic pulmonary nodules: a case report. BMC Womens Health 2017;17:81.

31. Veira-DaSilva AM, Alford CE, Levens ED, et a1. Favorable response to antigonadal therapy for a benign metastasizing leiomyoma. Obstet Gyneeol 2012;119:438-42.

32. Sawai Y, Shimizu T, Yamanaka Y, et al. Benign metastasizing leiomyoma and 18-FDG-PET/CT: A case report and literature review. Oncol Lett 2017;14:3641-6.

33. Naito M, Kobayashi T, Yoshida M, et al. Solitary pulmonary nodule of benign metastasizing leiomyoma associated with primary lung cancer: a case report. J Med Case Rep 2011;5:500.

34. Chen A, Sun T, Pu X, et al. Concurrent pulmonary benign metastasizing leiomyoma and primary lung adenocarcinoma: a case report. AME Case Rep 2018;2:18.

35. Kayser K, Zink S, Schneider T, et al. Benign metastasizing leiomyoma of the uterus: documentation of clinical, immunohistochemical and lectin-histochemical data of ten cases. Virchows Arch 2000;437:284-92.

36. Pacheco-Rodriguez G, Taveira-DaSilva AM, Moss J. Benign metastasizing leiomyoma. Clin Chest Med 2016;37:589-95.

37. Chen S, Zhang Y, Zhang J, et al. Pulmonary benign metastasizing leiomyoma from uterine leiomyoma. World J Surg Oncol 2013;11:163.

38. Taveira-DaSilva AM, Alford CE, Levens ED, et al. Favorable response to antigonadal therapy for a benign metastasizing leiomyoma. Obstet Gynecol 2012;119:438-42.
Cite this article as: Jiang H, Ma L, Qi XW, Yan LZ, Feng HX, Suo LJ, Liu B. Pulmonary benign metastasizing leiomyoma: a case report and literature review. Ann Palliat Med 2021;10(5):58315838. doi: 10.21037/apm-20-878 